\section{$\Delta$ rkivoc

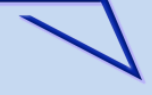

Archive for

Organic Chemistry
The Free Internet Journal

for Organic Chemistry
Review

Arkivoc 2017, part ii, 390-406

\title{
Conjugated arylenes: their convenient synthesis, luminescence characteristics, and applications
}

\author{
Jadwiga Sołoducho, ${ }^{* a}$ Dorota Zając, ${ }^{\text {a }}$ Joanna Cabaj, ${ }^{\text {a }}$ and Mieczysław Łapkowski ${ }^{\text {b }}$ \\ ${ }^{a}$ Wrocław University of Science and Technology, Faculty of Chemistry, Wybrzeże Wyspiańskiego 27, \\ 50-370 Wrocław, Poland \\ ${ }^{b}$ Silesian University of Technology, Faculty of Chemistry, Strzody 9, 44-100 Gliwice, Poland \\ E-mail: jadwiga.soloducho@pwr.edu.pl
}

Dedicated to Prof. Jacek Młochowski on the occasion of his $80^{\text {th }}$ anniversary

Received 06-13-2016

Accepted 09-20-2016

Published on line 12-04-2016

\section{Abstract}

Conjugated arylenes have significant perspectives as active materials useful in electronics, i.e. as semiconductors or solar cells. Organic semiconductors maintain the related processability, as with polymers, while retaining optoelectronic characteristics, i.e., high absorption coefficients of photons in the visible-region. This review summarizes recent developments in semiconducting polymers for electronic tools. This includes information on substitution and localization, branching, and its impact on functional materials.

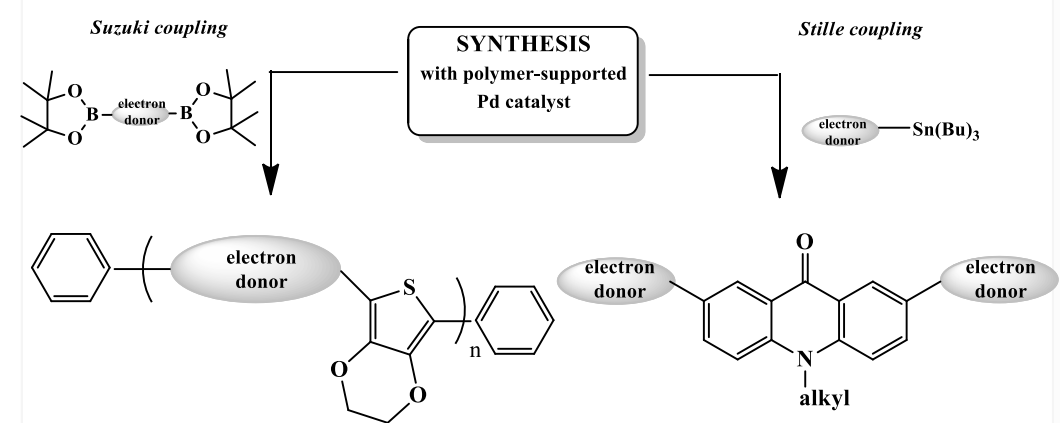

Keywords: Arylene derivatives, C-C coupling, polymerization, luminescent materials, electroactive materials 


\section{Table of Contents}

1. Introduction

2. $\pi$-Conjugated Precursors

\subsection{Synthesis}

2.1.1 Stille and Suzuki cross-coupling

2.1.2 Knoevenagel procedure

2.1.3 Polymerization procedures

2.2 Luminescence properties

2.3 Synthesized macrostructures in biosensing devices

3 Closing Remarks

4. Acknowledgments

References

\section{Introduction}

Conjugated polymeric semiconductors have proved notable in their role as a tenuous carrier transfer layer for OFETs, OLEDs as well as other molecular electronic devices. ${ }^{1-3}$ The simplicity of dilution as well as the retentive machine features, as well as the extensively perfected carrier transfer properties, have spurred a wide exploration of these semiconducting materials in the realms of both research and manufacturing. The adoption of elastic displays ${ }^{4}$ and circuitry $^{5,6}$ were suggested because they have individual electrical persistence and suit the price demands as well. The common techniques used in the majority of growth runs of organic semiconducting materials such as silicon derivatives, which have demonstrated suitable carrier mobility, and utility in the manufacturing processes to obtain plastics for use in various types of display.

There are several methods available for the synthesis of conjugated polymeric materials, i.e. Kumada process, Yamamoto polymerization, Suzuki-Miyaura polymerization, Heck polymerization, Sonogashira polymerization, Gilch polymerization, and Stille polymerization. ${ }^{1,7,8}$ However, as Okamoto and Luscombe have pertinently pointed out, ${ }^{7}$ the potential drawback of the reported methods is that it is often difficult to control the polydispersity, molecular weight, and the end groups of the polymers.

However, the Suzuki and Stille type reactions catalyzed by heterogeneous palladium using bromoarenes are comparatively well known, and polymer-supported catalysts have become valuable tools offering benefits such as simplification of product work-up, reuse of the catalyst, and facilitation of large-scale syntheses. The large number of publications signify that conjugated polymers are well-known in the literature. ${ }^{8}$

In conjugated polymers, the molecular architectonics, conformational order, packing and overall microstructure are known to have a significant influence on much of their optoelectronic properties, including their emission properties (EPs). ${ }^{1,2}$ These structural features, therefore, have to be controlled and tuned to exploit the EPs of this class of materials efficiently, i.e. in solution-processable, potentially large-area, flexible and lightweight optoelectronic structures such as organic light-emitting diodes (OLEDs) ${ }^{3,4}$, integrated in, for example, highly stretchable information displays. ${ }^{5,6}$ Emission can also be found in organic field-effect transistors ${ }^{7}$, while emission quenching (i.e. decrease of the emission intensity of a given system) is another important feature that is widely employed in organic photovoltaic devices (OPVs) to monitor the efficiency of charge transfer from the donor to the acceptor material. 8,9 
In the present work we describe a series of new symmetric/asymmetric ethylenedioxythiophene, acridone, and silicon derivatives $(\mathbf{1 , 2 , 4 , 5 )}$ with a heterocyclic core. Electrochemical and photophysical properties for few macrostructures are reviewed in detail.

\section{2. $\pi$-Conjugated Precursors}

\subsection{Synthesis}

2.1.1. Stille and Suzuki coupling. The Stille as well as Suzuki cross-couplings are classical palladium-catalyzed synthetic routes to obtain conjugated arylenes. The main advantages of Stille condensations are tolerance of many functional groups and mild reaction conditions. The organotin monomers can be conveniently prepared, and they are less sensitive to oxygen. ${ }^{17,18}$ Moreover, microwave irradiation was found to improve the average molecular weight of conjugated polyarylenes and yields. ${ }^{18}$

Suzuki condensations are also useful in the forming of $C s p^{2}-C_{s p} p^{2}$ bonds. This procedure is versatile in the synthesis of conducting polymers. Both methods, Suzuki and Stille cross-couplings (Scheme 1) were exploited to obtain branched or hyperbranched sterically crowded heterocyclic units. Suzuki coupling between dibromoarylenes and boronic acid derivatives was used for obtaining several oligomeric derivatives of 3,4ethylenedioxythiophene (EDOT). ${ }^{20}$ The procedure was subsequently performed using $\left.\mathrm{Pd}_{(\mathrm{PPh}}\right)_{4}$ as a catalyst. This reaction was carried out in dry toluene at $90^{\circ} \mathrm{C}$ for ca. 24 hours (Scheme 1).

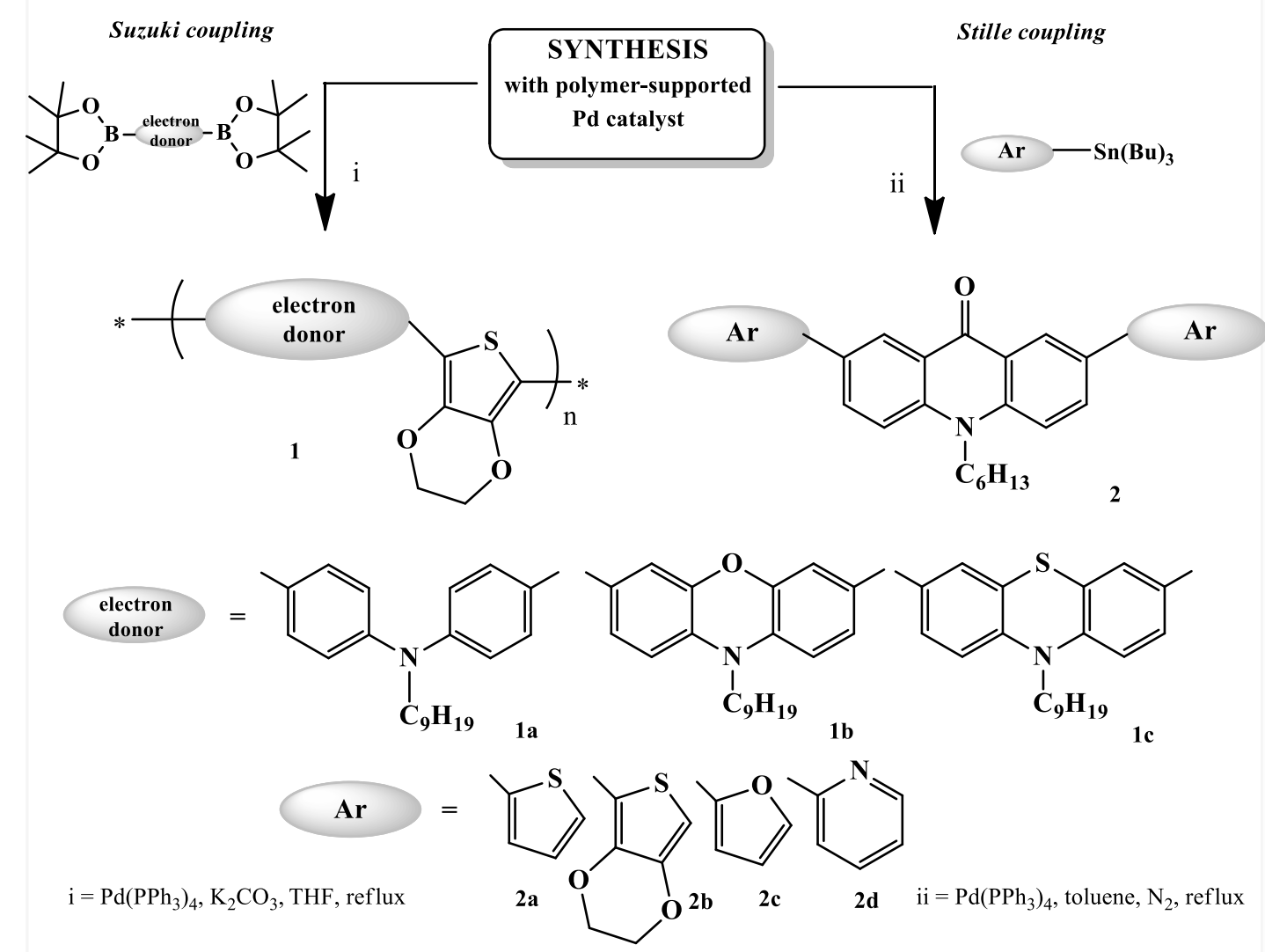

Scheme 1. The C-C coupling methods for macromolecular synthesis.

2.1.2. Knoevenagel procedure. The Knoevenagel method involves the coupling of a carbonyl moiety with compounds including a methylene group activated by one or two electron-withdrawing substituents (nitrile, 
acyl, or nitro). ${ }^{21-24}$ The asymmetric silane-based compounds $\mathbf{5 b}, \mathbf{c}$ were synthesized by Suzuki coupling reaction of 4-((4-bromophenyl) diphenylsilyl) derivative (3) and then Knoevenagel condensation with piperidine as catalyst (Scheme 2). The Knoevenagel condensation with piperidine as catalyst may proceed via one of two mechanisms that depend on the nature of the solid base. For strong bases, immediate deprotonation of the methylene group on the catalyst surface and reaction of the deprotonated intermediate with the benzaldehyde occurs, leading to the product. When weaker bases, such as amino groups are utilised in the catalytic process, creation of an imine intermediate with the benzaldehyde occurs (Schiff base). As a consequence of the higher basicity of the formed benzaldimine (compared to the free amine) deprotonation of the methylene group takes place followed by reaction, regenerating the active site. The active methylene group may also react immediately with amino groups to form amides, which inhibits the interaction of amine benzaldehyde and causes the deactivation of the catalyst. ${ }^{25}$

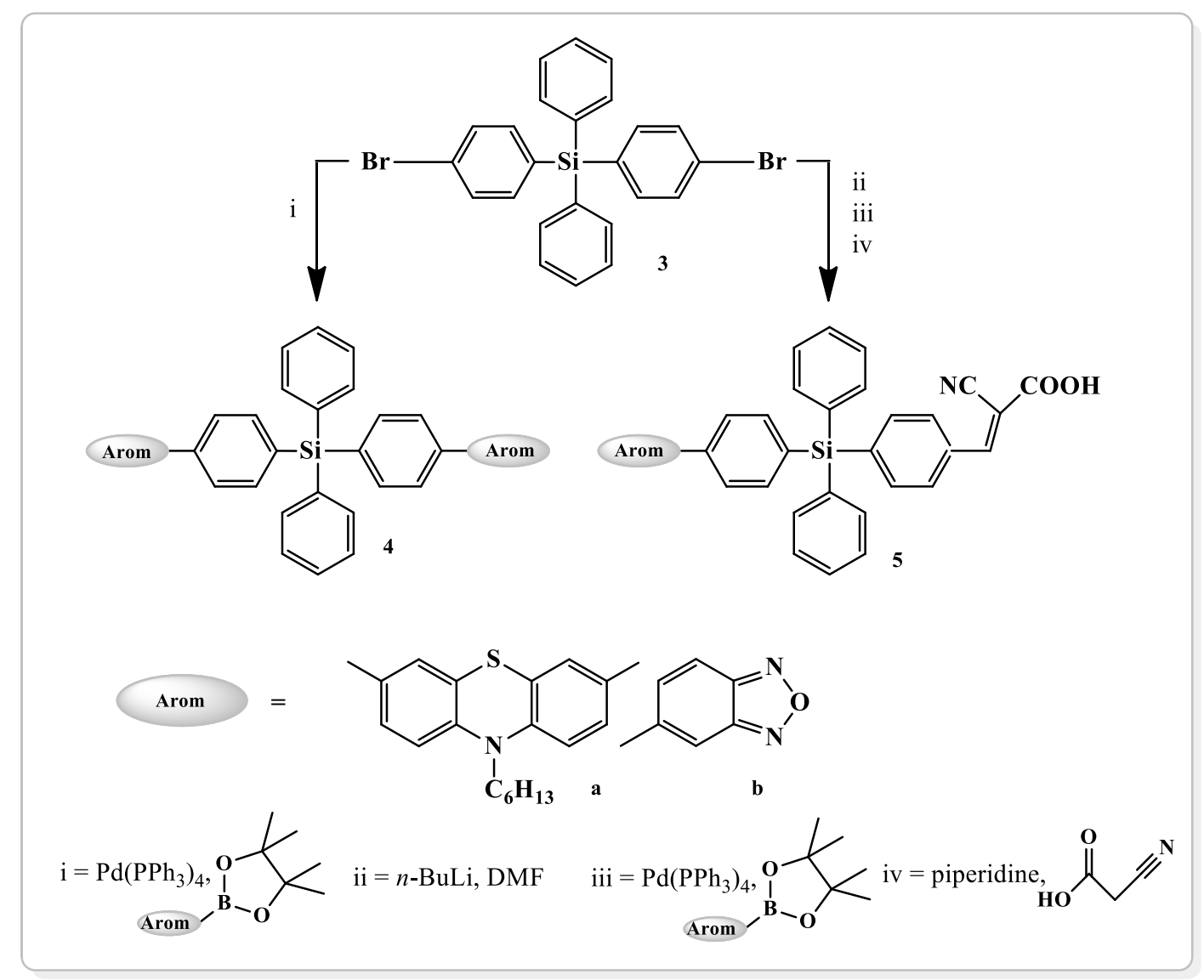

Scheme 2. The synthetic pathway for symmetric/asymmetric silane-based macrostructures.

2.1.3. Polymerization procedures. Suzuki reactions are very advantageous in the formation of $C s p^{2}-C s p^{2}$ bonds. This procedure is also suitable in the synthesis of conducting polymers. The Suzuki reaction is also a powerful tool for the formation of $c s p^{2}-C s p^{3}$ bonds. This condensation was implemented in our work in which branched or hyper-branched sterically crowded heterocyclic structures were obtained. ${ }^{26,27}$

Suzuki coupling of dibromobenzothiadiazole and boronic acid derivatives (7) was performed using a $\mathrm{Pd}\left(\mathrm{PPh}_{3}\right)_{4}$. The synthesis of phenothiazine/phenoxazine oligomers $(\mathbf{8} \mathbf{a}, \mathbf{b})$ is shown in Scheme 3 . This type of synthesis was carried out under the standard conditions reported earlier by Nowakowska-Oleksy, A. et al- ${ }^{26}$ 


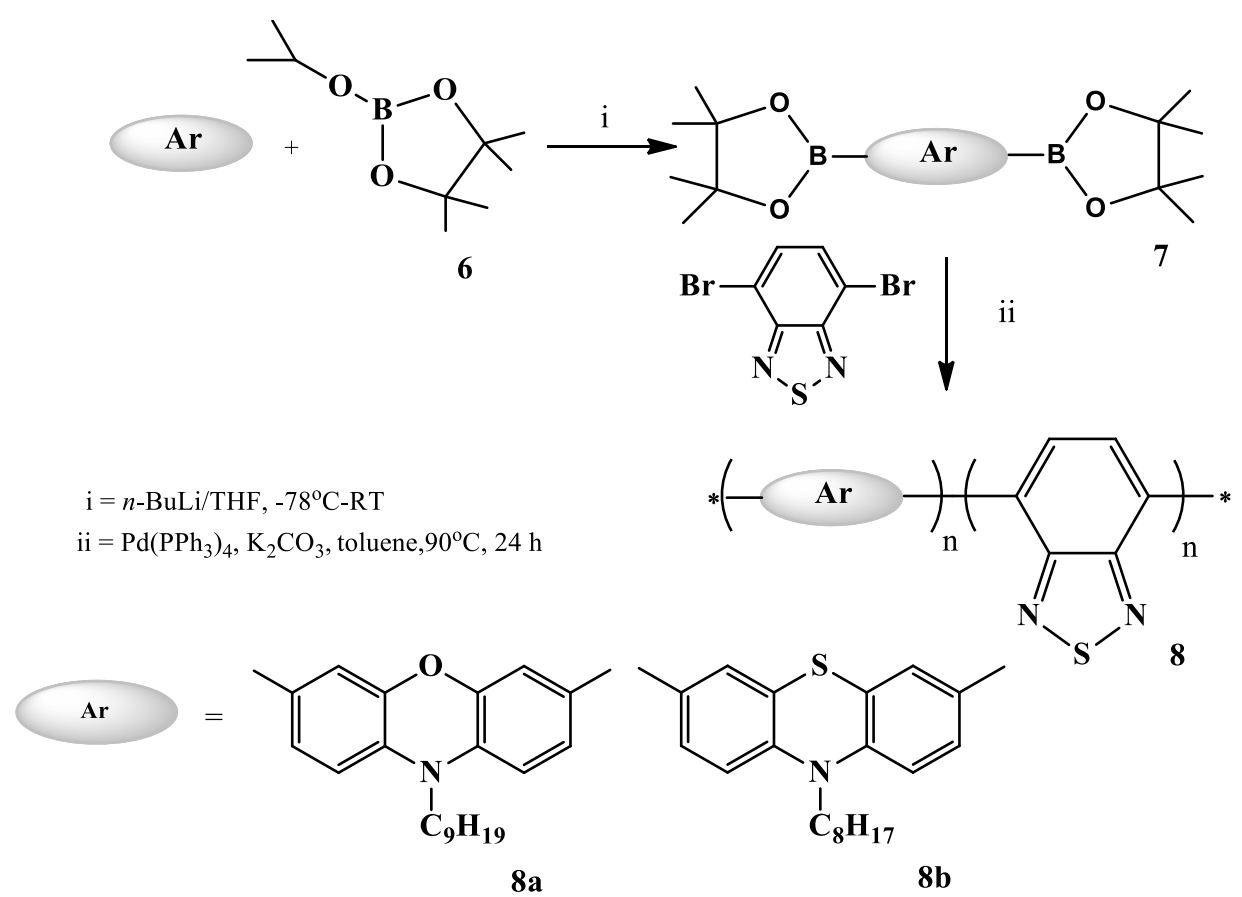

Scheme 3. The synthetic pathway for symmetric phenothiazine/phenoxazine oligomers.

It was determined that the oligomers $(\mathbf{8} \mathbf{a}, \mathbf{b})$ were all of low molecular weight with number-average molecular weights of about $3500-3600 \mathrm{~g} / \mathrm{mol}$. This value nearly-corresponds to a degree of polymerization of seven to eight, meaning that the synthesized units have an average of about 30 aromatic rings per chain. ${ }^{26}$ The molecular weights obtained were adequate for processing and film formation, and so further optimization of the polymerization was not attempted.

Many researchers have also investigated the electrochemical copolymerization between two commercial available monomers such as EDOT, thiophene or pyrrole. ${ }^{28,29}$ To achieve favorable copolymerization, the applied monomers should have close and low onset oxidation potentials. ${ }^{30}$ However, electrochemical copolymerization can also be successfully carried out in $\mathrm{Et}_{2} \mathrm{O} \cdot \mathrm{BF}_{3}$ (BFEE) system for many monomers, which cannot be used as co-monomers in acetonitrile ( $\mathrm{ACN}$ ) or aqueous systems.

Due to the low onset potential of EDOT, the copolymerization process is similar to the homopolymerization of EDOT. ${ }^{31}$ It can be noted that the onset potentials of the copolymerization systems are below $0.8 \mathrm{~V}$, which is much lower than that in ACN or aqueous solutions, especially the polymerization of thiophene, indicating the low-potential electrochemical copolymerization in BFEE. ${ }^{32}$ The low-potential copolymerization can lead to high quality copolymers. For structural, morphological, electrochemical and spectroelectrochemical characterizations, the copolymer layers are electrochemically deposited via potentiostatic $0.92 \mathrm{~V}$ with the same polymerization charge, after polymerization, the obtained layers were rinsed in ACN and dried in vacuum at $40{ }^{\circ} \mathrm{C}$ for $24 \mathrm{~h}$.

The derived polymers possess good electrochromic properties such as multicolor electrochromicity, fast switching rate and good stability. Due to the strong electron-donor character of EDOT, a red-shift in the absorption spectra was observed for the EDOT-based copolymers in comparison with their thiophene-based counterparts. Furthermore, the prepared copolymers present rational optical contrast, fast switching rate, and adequate stability. ${ }^{20}$ 


\subsection{Luminescence properties}

For a better understanding of the EP phenomena of conjugated polymers (CPs), it is crucial first to define the most relevant phenomena. Emission of light-relates to the luminescence of a material, i.e. the light effect is rather a form of cold body radiation. Consequently, luminescence may be regarded as a combined result of different chemical or physical procedures. For example, when a polymer absorbs a photon the system is excited both electronically and vibrationally. Light emission from a material after the absorption of photons is called photoluminescence (PL). The emitted light is of a longer wavelength, i.e. lower energy, than the wavelength of the absorbed photons. These phenomena have found many practical applications, including $\mathrm{FL}$ spectroscopy and microscopy. ${ }^{33}$ Many other types of luminescence phenomena exist, including chemiluminescence (emission of light as a result of a chemical reaction) or electroluminescence (EL). The latter is important from a technological point of view. Defined as the luminescence of a material that corresponds to either an applied electric current or a strong electric field (leading to a radiative recombination of electrons and holes), EL has found an application in electroluminescent tools including OLEDs. ${ }^{3}$

In all cases of studied synthesized molecules fluorescence activity was observed. Figure 1 shows the fluorescence excitation and emission spectra of ethylenedioxythiophene macrocyclic derivatives 1a-c dissolved in dichloromethane.

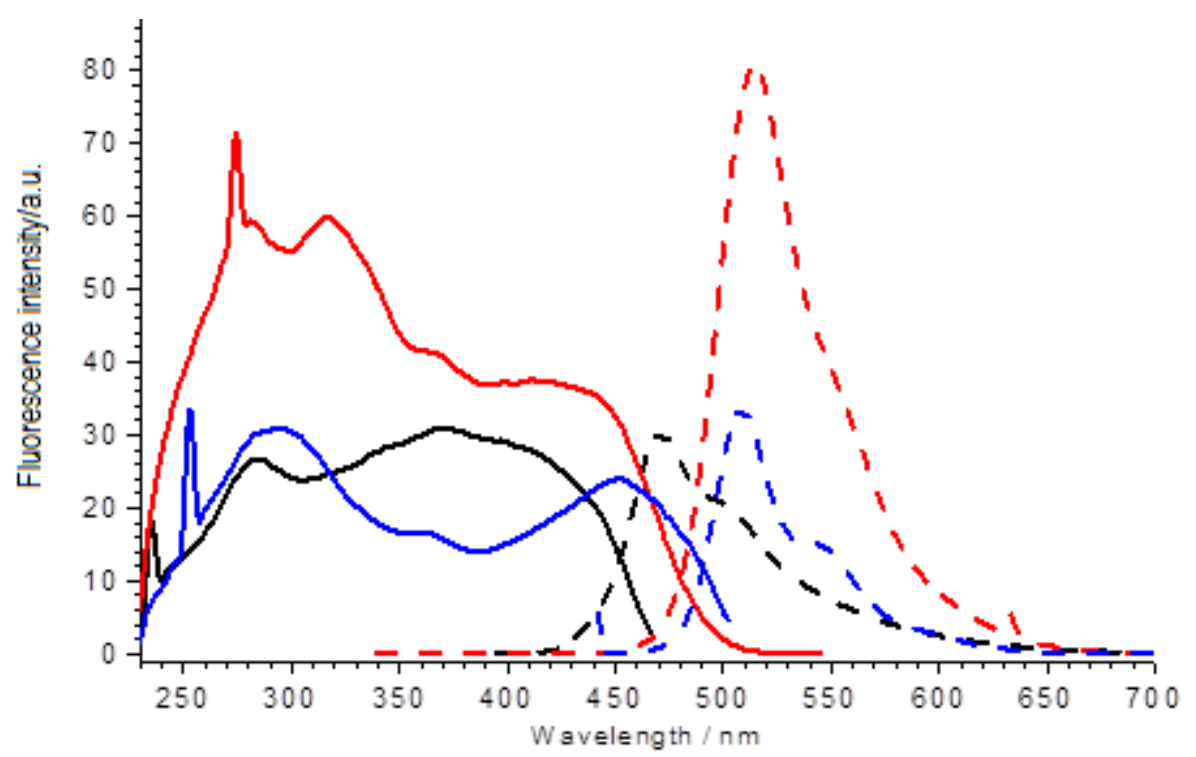

Figure 1. The fluorescence excitation (solid line) and emission (dashed line) spectra of 1a-c dissolved in dichloromethane; $\mathbf{1 a}$ - black line; $\mathbf{1} \mathbf{b}$ - red line; $\mathbf{1} \mathbf{c}$ - blue line.

Fluorescence spectra of 1a-c were recorded at excitation values equal of maxima of absorption. Excitation of at $370 \mathrm{~nm}$ led to the emission with a maximum at $471 \mathrm{~nm}$. The excitation spectrum of compound $\mathbf{1 b}$ has a maximum at $292 \mathrm{~nm}$, the emission spectrum was found at $508 \mathrm{~nm}$. The insertion an oxygen bridge between benzene rings results in a significant bathochromic shift. The excitation of $1 \mathrm{c}$ at $317 \mathrm{~nm}$ resulted in an emission with maximum at $515 \mathrm{~nm}$. The replacement of the oxygen with sulfur led to a bathochromic effect. ${ }^{20}$

Spectroelectrochemical investigation of ethylenedioxythiophene derivatives (Figure 2) revealed upon oxidation, an absorption peak at $505 \mathrm{~nm}$ notably different from the absorption spectrum of bis-EDOT. ${ }^{25}$ When the applied potential is staircased back down to open circuit potential (OCP), this absorption signal diminishes, responding to the shifting result between the rate of the electrochemical generation of the cation radical and the rate of the chemical reaction terminating the cation radical. 
The electrochemical behavior of $\mathbf{5 a}$ and $\mathbf{4 a}$ (Figure 1) is identical, and is saved for the magnitude of the faradaic current observed for the reversible redox pair, centered at $+0.29 \mathrm{~V} .{ }^{25}$

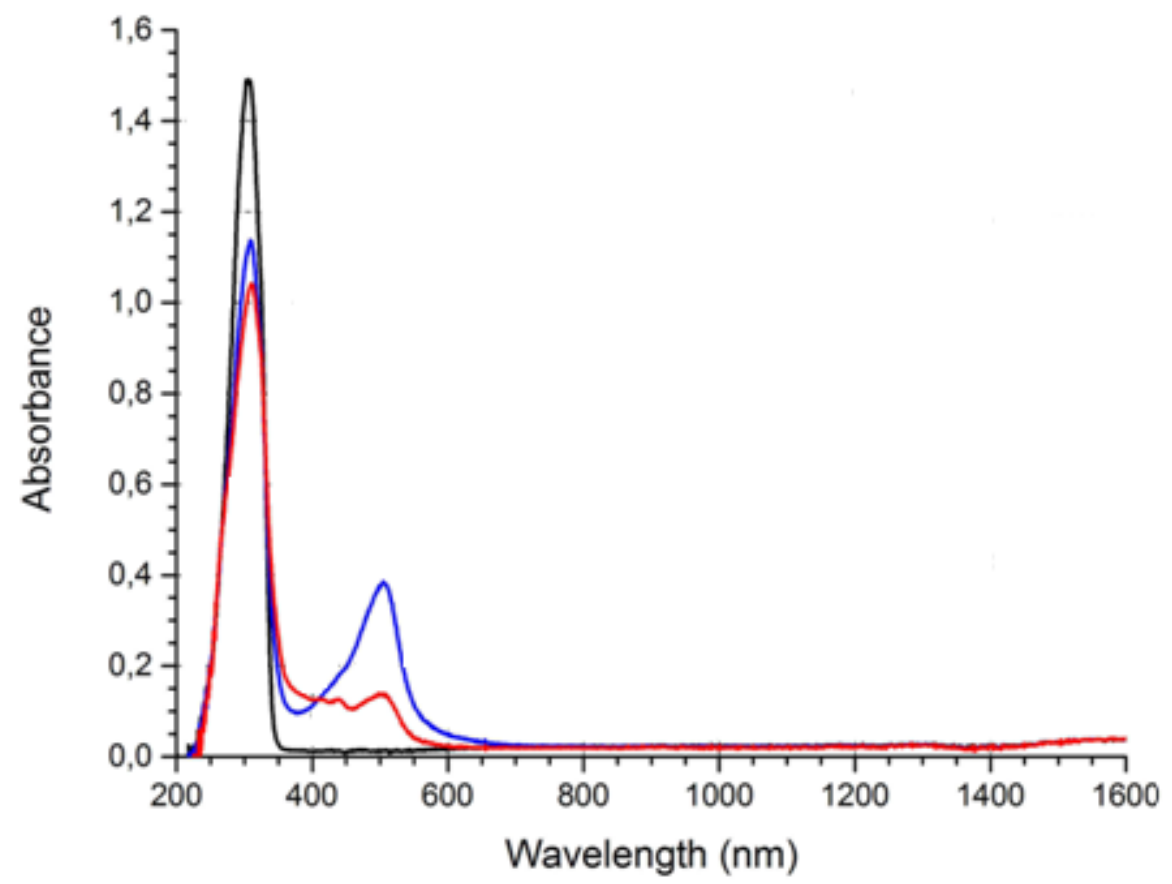

Figure 2. UV-Vis-NIR spectroelectrochemical investigation of 5a. Absorption spectra registered at 0.0V (black line), after staircasing up to $+1.0 \mathrm{~V}$ (blue line) and after staircasing down to 0.0V (red line).

The optical absorption spectra of the two systems (Figure 3) in the ground state are similar in shape. The EPR spectrum of $\mathbf{4 a}$ (Figure 3a) is typical for phenothiazines, with several components of the spectral line overlapping destructively and yielding a central region, $(337.75 \div 338.75 \mathrm{mT})$ in which they cancel each other out. Although, such a spectrum provides little information about the structure of the electro-generated radical cation, it also excludes any significant degree of communication between the radical cations present on the two phenothiazine moieties of $\mathbf{4 a}$. For $\mathbf{5 a}$ (Figure $3 \mathrm{~b}$ ), line splitting was observed, similar to that which was found in our earlier work on a thiophene-bis-substituted phenothiazine derivative. ${ }^{34}$ The changes in the shape of the spectrum in relation to that of 4 a result from a different relaxation path, and hence a change in line width is observed.

a)

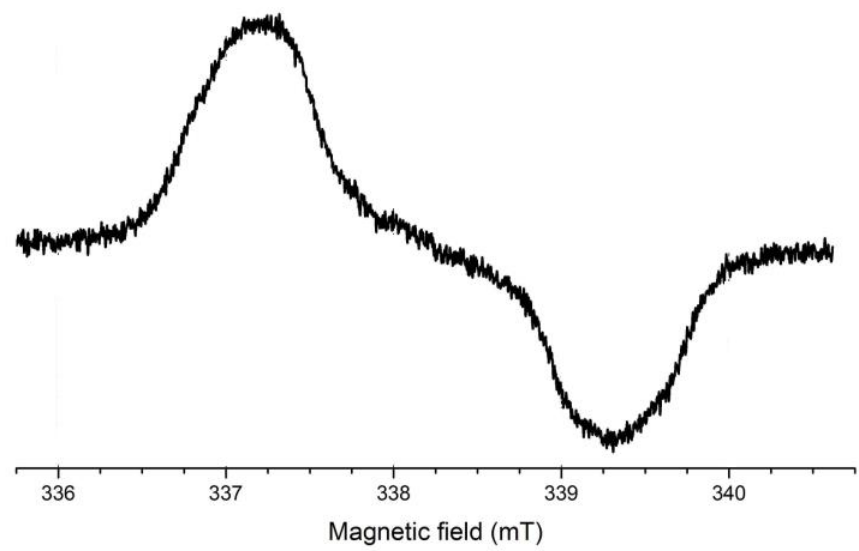

b)

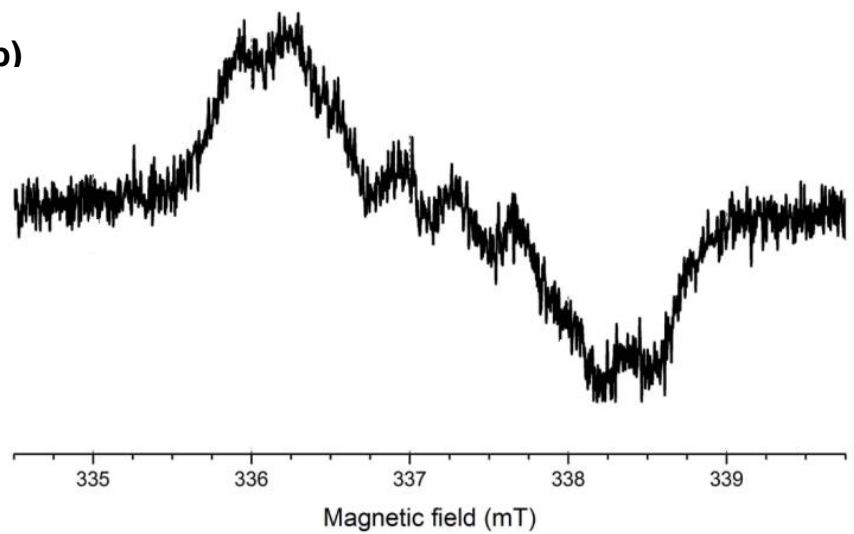

Figure 3. Electron paramagnetic resonance spectra of species electro-generated from the investigated compounds a) 4 a radical cation; b) 5 a radical cation. 
Comparing the asymmetric $\mathbf{5 a}$ and the symmetric $\mathbf{4 a}$ silanes, the derivative $\mathbf{5 a}$ is redshifted in the light emission spectrum due to the electron-withdrawing 2-cyano-propenoic acid group, making it a better pushpull system. The quantum yields $\left(\Phi_{F}\right)$ of $4 a, 5 a$, in $\mathrm{CH}_{2} \mathrm{Cl}_{2}$ are found as good in range $(0.524-0.673)$.

The spectroelectrochemical features of the poly-acridones were investigated in order to find the relationship between redox processes and UV-Vis absorption. ${ }^{35} \mathrm{UV}$-Vis spectra of $p$-doping acridones were recorded with increasing applied electrode potential as shown in Figure 4. The absorption bands corresponding to the obtained polymers (340 nm for poly(2b), $331 \mathrm{~nm}$ for poly(2a)) were observed on lower intensity as the applied potential gradually increased. A well-defined absorption band of charge carriers as the first oxidation potential appears in the range of 500-800 nm for both of the polymers (poly-2b, poly-2a), according to formation of polarons proved by ESR spectroelectrochemistry. Generation of the other charge carriers, bipolarons absorbing in the infrared region, is also noted with the growth of applied potential of polymer $\mathbf{2} \mathbf{b}$. The bipolaron band is wider in the case of thiophene derivative $\mathbf{2 a}$ (600 $\mathrm{nm}$ to $1700 \mathrm{~nm}$ ) and overlaps the polaronic band.
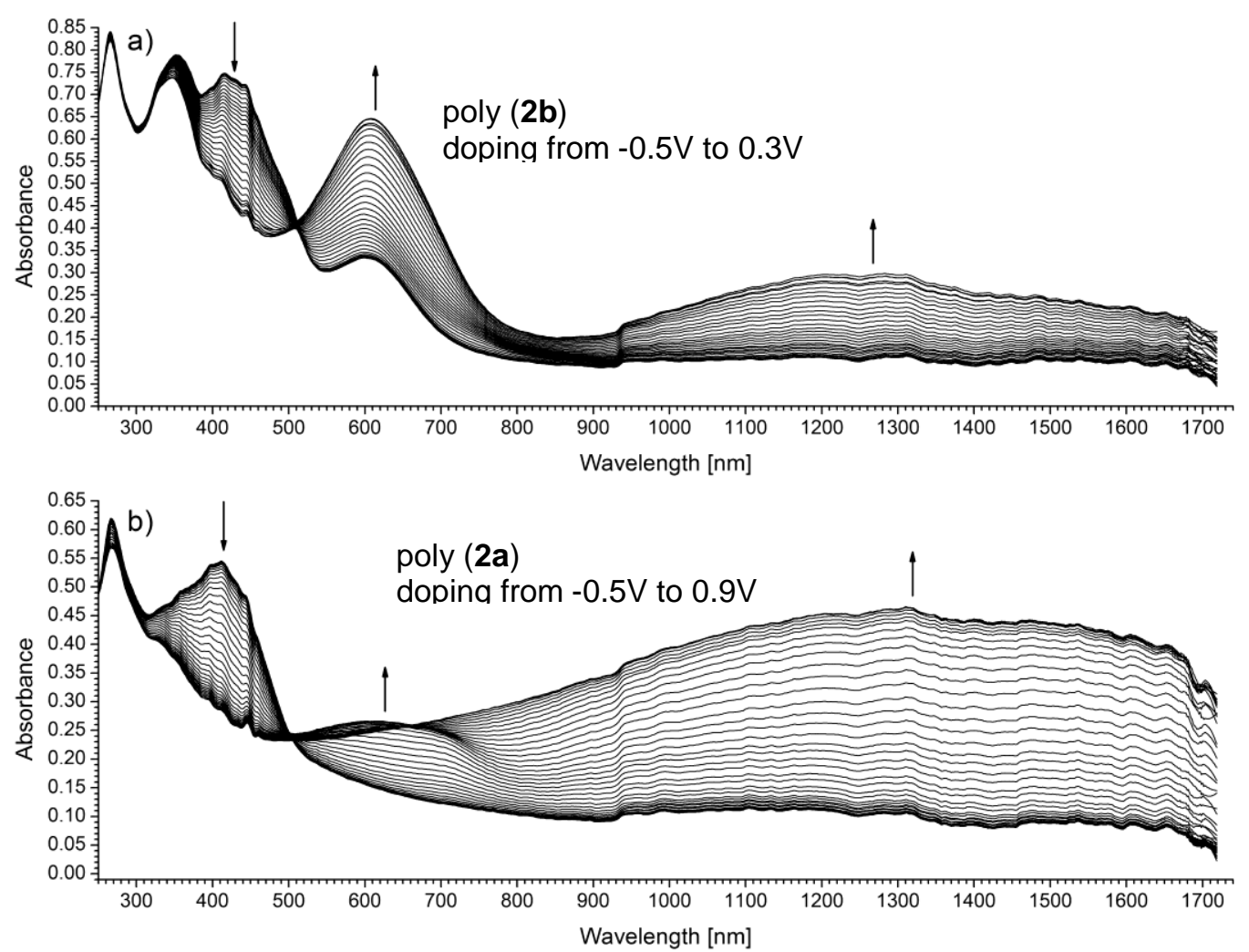

Figure 4. UV-Vis spectra recorded during electrochemical oxidation of polymeric films in monomer-free medium, a) poly(2b), b) poly(2a).

Acridones have rather high luminescence quantum yields and are known as efficient laser dyes ${ }^{36}$ and fluorescence sensors. ${ }^{37,38}$ Due to the acridone emission maximum close to $500 \mathrm{~nm}$, branched conjugated units with acridone bridges are advantageous for conducting and fluorescent materials. The benefits of such heterocyclic structures include chemical inertness, notable resistance to photobleaching and also the possibility to be excited around $400-420 \mathrm{~nm}^{39}$

The excitation and emission spectra of acridones were measured in a dilute chloroform solution (Figure 5). The maximum fluorescent excitation wavelength of $\mathbf{2 b}$ was located at $467 \mathrm{~nm}$, and the corresponding 
emission wavelength was located at $504 \mathrm{~nm}$ with a full spectral width at half maximum (FWHM) $-52 \mathrm{~nm}$. The low values of FWHM $(<70 \mathrm{~nm})^{40}$ are responsible for high color purity and its saturation. Stokes shifts calculated as $154 \mathrm{~nm}$ were observed at $126 \mathrm{~nm}$ and $118 \mathrm{~nm}$ for 2a, 2c, respectively (Table 1). These broad Stokes shifts are desirable as re-absorption of the emitted photons can be minimized. The values of Stokes shifts are rather similar which means that it is essentially an acridone emission.

Table 1. Photophysical data of acridone derivatives

\begin{tabular}{|c|c|c|c|c|c|}
\hline Compound & abs $\lambda_{\max }{ }^{a}(n m)$ & $\varepsilon^{a} \times 10^{-4}$ & $\lambda_{\max }{ }^{b}(n m)$ & $\Delta_{\text {stokes }}(\mathrm{nm})$ & $\phi_{f}$ \\
\hline $2 a$ & $269,338,420$ & $\begin{array}{c}2.64,3.32 \\
4.12\end{array}$ & 464 & 126 & 0.42 \\
\hline $2 b$ & $273,350,425$ & $\begin{array}{c}2.68,3.44 \\
4.17\end{array}$ & 504 & 154 & 0.45 \\
\hline $2 c$ & $267,298,350$ & $\begin{array}{l}2.62 \\
2.93 \\
3.44\end{array}$ & 471 & 121 & 0.36 \\
\hline
\end{tabular}

a One-photon absorption maxima $(\mathrm{nm})$ and coefficients $\left(\varepsilon\right.$ was in unit of $\left.\mathrm{dm}^{3} \mathrm{~mol}^{-1} \mathrm{~cm}^{-1}\right) .{ }^{b}$ One-photon emission fluorescence maxima ( $\mathrm{nm})$.

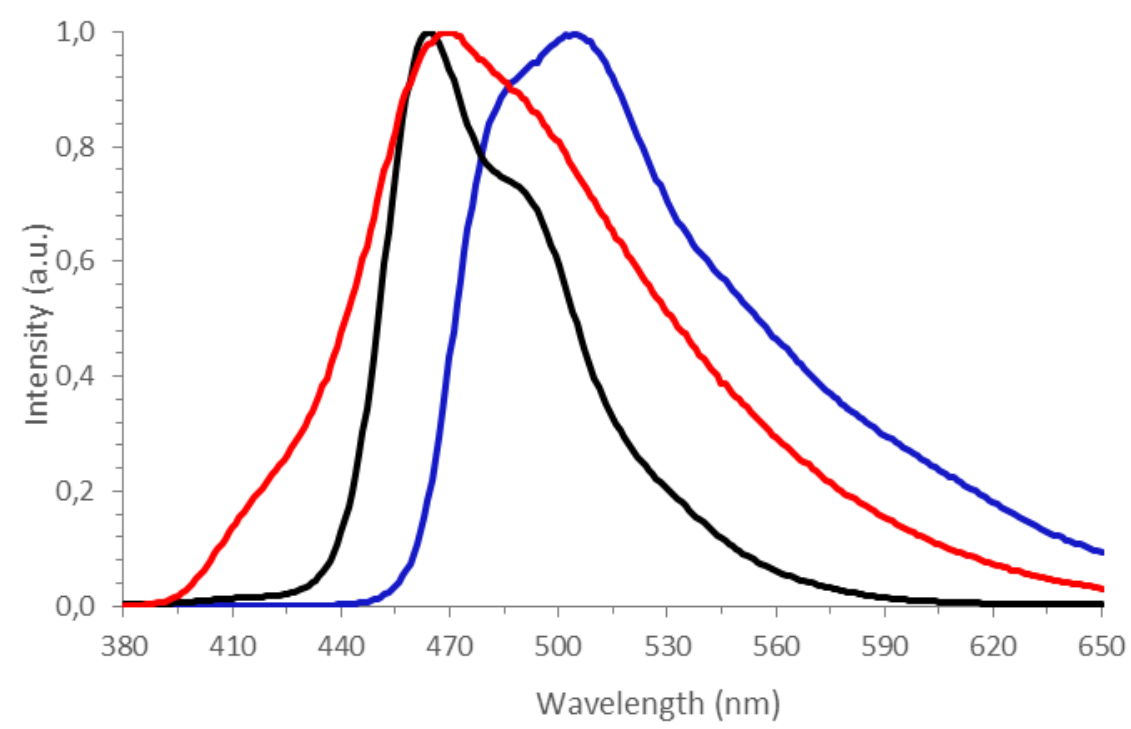

Figure 5. The fluorescence emission spectra of 2 a-c dissolved in chloroform $\left(10^{-6} \mathrm{~mol} / \mathrm{dm}^{3}\right) ; 2 \mathrm{a}-$ black line; $\mathbf{2} \mathbf{b}$ - blue line; $\mathbf{2 c}$ - red line.

\subsection{Synthesized macrostructures in biosensing devices}

CPs are prospectively subservient for the fabrication of miniaturized sensors that enable small sample volumes, portability, and high-density arrays. Nanostructured CPs are advantageous for electron transport and biomolecule stabilization due to their growing surface area and high surface-free-energy. Nanostructured CPs, such as polypyrrole, polyaniline and polythiophene, offer excellent perspectives for both interfacing biological recognition species and transducing electronic signals to construct modern bioelectronic devices. ${ }^{41}$ 
The two dimensional polymeric surfaces modified biosensor electrodes were also successful in our earlier experience. $^{42,43}$

In other work, sensing systems where a platinum electrode was modified by the electrochemical polymerization. A suitable example is a thin polymer layer built of 3-methylthiophene/3-thiopheneacetic acid/2,7-bis[2-(3,4-ethylenedioxythiophene)]-N-nonylacridone (2b). ${ }^{42}$ The electropolymerized layer exists in the conducting oxidized state. The optimal current density for copolymer deposition was observed as 12 $\mathrm{mA} / \mathrm{cm}^{2}$, and the polymerization time was found to be 1 minute. ${ }^{42}$ A CPs porous layer was applied as proper matrix for enzyme - laccase immobilization. The immobilization of enzyme was performed in a one step process. It was carried out for 10 minutes under galvanostatic conditions applying current $3 \mathrm{~mA} / \mathrm{cm}^{2}$. The optimal conditions presented in the experimental part were obtained considering a high signal-noise ratio, and stability of biosensor response. ${ }^{42}$ On the other hand, poly( $N$-hexyl-2,7-bis(thiophene)acridone) was exploited by us in a ceramic optical biosensor designed for permanent monitoring of water solutions (Figure 6). ${ }^{43}$
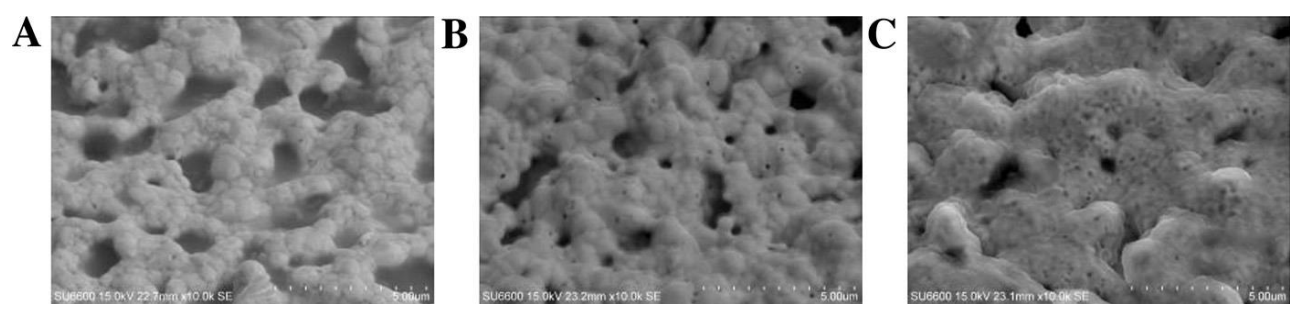

Figure 6. SEM images of: A - platinum bare electrode, B - electrode modified with polymer, C-electrode modified with polymer and laccase. Adopted from Jędrychowska et al. ${ }^{43}$

\section{Conclusions}

During the past decade the electron-withdrawing unit/electron-donor substituent introduced into $\pi$-electron frameworks has proven to be an advantageous pathway to enlarge electron injection and carrier mobility. Many $\pi$-conjugated structures have been designed, synthesized, and validated as effective semiconductors.

Since first reported by Miyaura and Suzuki in 1979, the palladium-catalyzed cross-coupling reactions of organoboron derivatives with organic electrophiles have been widely implemented in both academic and industrial laboratories and have consequently supported the effective synthesis on a large scale of interesting compounds including pharmaceuticals, agrochemicals and synthetic intermediates. Although, in recent years, many new transition metal-catalyzed methods allowing $\mathrm{C}-\mathrm{C}$ bond formation have been investigated, the Suzuki-Miyaura coupling is still one of the most rational tool for installing a wide range of non-functionalized and functionalized carbon substituents on (hetero)aromatic systems with exquisite chemo- and site-selectivity and is by far the most versatile method for the synthesis of industrially relevant functionalized heteroarenes and unsymmetrical biheteroaryl derivatives.

Herein, an efficient synthetic procedures for obtaining arylene derivatives of ethylenedioxythiophene, acridone and tetraphenyl-silane is reported. The synthesized branched units are able to couple to copolymers by electrochemical and chemical proceedures. The polymers are thermally stable materials, which lose a little of their weight when heated. 
The utility of the polymerization method is demonstrated i.e. by the synthesis of polyphenothiazine derivatives. Because of the formation of rings in the polymerization process, the polymers comprised alternating units. It is anticipated that further optimization of polymerization conditions and new efforts in molecular structure design will make the click polymerization a more versatile synthetic tool for the generation of new advanced materials.

The obtained semiconducting units with electron-deficient acridones exhibit intensive luminescence in blue or green region and can be cast into uniform films (Table 2). They possess moderate to good fluorescence quantum yields.

The novel light-emitting copolymers derived from acridone and different bis(heterocycle) rings were obtained also by oxidative electropolymerization. The incorporation of the bis(heterocycle) units into the polyacridone main chain can significantly improve the stability and decrease the ionization potential of these type of polymers.

The compounds based on 3,4-ethylenedioxythiophene exhibit blue emission (Table 2). The onset of the oxidation wave was found at rather low potentials. The optical band gap, between 2.1 and $2.5 \mathrm{eV}$ was deduced from absorption spectra of the undoped polymer.

The results reported in the paper concern the investigation of alternating oligomers of EDOT. All compounds are electronically and optically active. All of macrostructures appear to be stable during multiple doping and dedoping processes.

Equally, all compounds based on tetraphenylsilane are electronically and optically active (Table 2).

Table 2. Optical properties of reported derivatives

\begin{tabular}{ccccc}
\hline compound & abs $\lambda_{\max }{ }^{a}(\mathrm{~nm})$ & $\lambda_{\max }{ }^{b}(\mathrm{~nm})$ & $\phi_{\mathrm{f}}{ }^{c}$ & Ref. \\
\hline 1a & 406 & 471 & - & 20 \\
1b & 442 & 508 & - & 20 \\
$\mathbf{1 c}$ & 422 & 515 & - & 20 \\
$\mathbf{2 a}$ & $269,338,420$ & 464 & 0.42 & 35 \\
$\mathbf{2 b}$ & $273,350,425$ & 504 & 0.45 & 35 \\
$\mathbf{2 c}$ & $267,298,350$ & 471 & 0.36 & 35 \\
$\mathbf{4 a}$ & 334 & 481 & 0.615 & 25 \\
$\mathbf{4 b}$ & 315 & 433 & 0.524 & 25 \\
$\mathbf{5 a}$ & 314 & 553 & 0.632 & 25 \\
$\mathbf{8 a}$ & 280 & 476 & 0.420 & 26 \\
$\mathbf{8 b}$ & 284 & 480 & 0.480 & 26 \\
\hline
\end{tabular}

a One-photon absorption maxima $(\mathrm{nm}) .{ }^{\mathrm{b}}$ One-photon emission fluorescence maxima (nm).

${ }^{c}$ The quantum yields were determined using quinine sulfate in $0.5 \mathrm{~mol} / \mathrm{dm}^{3}$ sulfuric acid $\left(\phi_{\mathrm{f}}=0.546\right)$.

The lowest electrochemical and optical band gap characterizes the symmetric structure containing phenothiazine unit $\mathbf{4 a}$, the largest - the structure with a benzofurazan moiety $\mathbf{- 5 b}$. Electrochemical properties of the investigated compounds make this material of great interest for electrochromic applications. Moreover, EPR spectra provide little information about the structure of the electro-generated radical cations, it also 
excludes any significant degree of communication between the radical cations present on the two phenothiazine moieties of $4 a$.

All the synthesized compounds are electronically and optically active. All of macrostructures appear to be stable during multiple doping and dedoping processes. The electrochemical properties of the investigated compounds make these materials of great interest for electroptical applications.

\section{Acknowledgements}

The Authors are thankful for financial support from the Wrocław University of Science and Technology.

\section{References}

1. Arias, A. C.; MacKenzie, J. D.; McCulloch, I.; Rivnay J.; Salleo, A. Chem. Rev. 2010, 110, 3. http://dx.doi.org/10.1021/cr900150b

2. Loo, Y.-L.; McCulloch, I. MRS Bull. 2008, 33, 653.

http://dx.doi.org/10.1557/mrs2008.149

3. Gelinck, G.; Heremans, P.; Nomoto, K.; Anthopoulos, T. D. Adv. Mater. 2010, 22, 3778. http://dx.doi.org/10.1002/adma.200903559

4. Chabinyc, M. L.; Salleo, A. Chem. Mater. 2004, 16, 4509. http://dx.doi.org/10.1021/cm049647z

5. Gelinck, G. H.; Huitema, H. E. A.; van Veenendaal, E.; Cantatore, E.; Schrijnemakers, L.; van der Putten, J. B. P. H.; Geuns, T. C. T.; Beenhakkers, M.; Giesbers, J. B.; Huisman, B.-H.; Meijer, E. J.; Benito, E. M.; Touwslager, F. J.; Marsman, A. W.; van Rens, B. J. E.; de Leeuw, D. M. Nat. Mater. 2004, 3, 106. http://dx.doi.org/10.1038/nmat1061

6. Dodabalapur, A. Mater. Today 2006, 9, 24. http://dx.doi.org/10.1016/S1369-7021(06)71444-4

7. Okamoto, K.; Luscombe, C.K. Polym. Chem. 2011, 2, 2424.

http://dx.doi.org/10.1039/c1py00171j

8. Cheng, Y.J.; Yang, S.H.; Hsu, C.S. Chem. Rev. 2009, 109, 5868.

http://dx.doi.org/10.1021/cr900182s

9. Como, E. D.; Borys, N. J.; Strohriegl, P.; Walter, M. J.; Lupton, J. M. J. Am. Chem. Soc. 2011, $133,3690$. http://dx.doi.org/10.1021/ja109342t

10. Botiz, I.; Stingelin, N. Materials 2014, 7, 2273.

http://dx.doi.org/10.3390/ma7032273

11. Burroughes, J. H.; Bradley, D. D. C.; Brown, A. R.; Marks, R. N.; Mackay, K.; Friend, R. H.; Burn, P. L.; Holmes, A. B. Nature 1990, 347, 539. http://dx.doi.org/10.1038/347539a0

12. Guha, S.; Chandrasekhar, M.; Scherf, U.; Knaapila, M. Phys. Status Solidi B, 2011, 248, 1083. http://dx.doi.org/10.1002/pssb.201000779

13. Liang, J.; Li, L.; Niu, X.; Yu, Z.; Pei Q. Nat. Photonics, 2013, 7, 817. http://dx.doi.org/10.1038/nphoton.2013.242 
14. Yun, S.; Park, S.; Park, B.; Park, S. K.; Prahlad, H.; von Guggenberg, P.; Kyung, K.-U. IEEE/ASME Trans. Mechatronics 2014, 19,1463.

http://dx.doi.org/10.1109/TMECH.2013.2292956

15. Roelofs, W. S. C.; Adriaans, W. H.; Janssen, R. A. J.; Kemerink, M.; de Leeuw, D. M. Adv. Funct. Mater. 2013, 23, 4133.

http://dx.doi.org/10.1002/adfm.201203568

16. Li, W.; Hendriks, K. H.; Furlan, A.; Roelofs, W.; Meskers, S. C.; Wienk, M. M.; Janssen, R. A. J. Adv. Mater. 2014, 26, 1565.

http://dx.doi.org/10.1002/adma.201304360

17. Botiz, I.; Darling, S. B. Macromolecules, 2009, 42, 8211.

http://dx.doi.org/10.1021/ma901420h

18. Huang, H.; Jiang, H.; Chen, K.; Liu, H. J. Org. Chem. 2009, 74, 5599.

http://dx.doi.org/10.1021/jo9005206

19. Lerebours, R.; Camacho-Soto, A.; Wolf, C. J. Org. Chem. 2005, 70, 8601.

http://dx.doi.org/10.1021/jo051257o

20. Olech, K.; Sołoducho, J.; Łaba, K.; Data, P.; Łapkowski, M.; Roszak, S. Electrochim. Acta 2014, 141, 349. http://dx.doi.org/10.1016/j.electacta.2014.07.084

21. Angeletti, E.; Canepa, C.; Martinetti, G.; Venturello, P. J. Chem. Soc., Perkin Trans. 1 1989, 105. http://dx.doi.org/10.1039/p19890000105

22. Seki, T.; Onaka, M. J. Mol. Catal. A: Chem. 2007, 263, 115.

http://dx.doi.org/10.1016/j.molcata.2006.08.049

23. Saravanamurugan, S.; Palanichamy, M.; Hartmann, M.; Murugesan, V. Appl. Catal. A 2006, $298,8$. http://dx.doi.org/10.1016/j.apcata.2005.09.014

24. Wirz, R.; Ferri, D.; Baiker, A., Langmuir, 2006, 22, 3698.

http://dx.doi.org/10.1021/la053145y

25. Zając, D.; Sołoducho, J.; Jarosz, T.; Łapkowski, M.; Roszak, S. Electrochim. Acta, 2015, 173, 105. http://dx.doi.org/10.1016/j.electacta.2015.05.038

26. Nowakowska-Oleksy, A.; Cabaj, J.; Olech, K.; Sołoducho J. J. Fluoresc. 2011, 21, 1625. http://dx.doi.org/10.1007/s10895-011-0851-1

27. Świst, A.; Sołoducho, J.; Data, P.; Łapkowski, M., Arkivoc 2012, (iii), 193.

28. Sapstead, R. M.; Corden, N.; Hillman, A. R. Electrochim. Acta, 2015, 162, 119. http://dx.doi.org/10.1016/j.electacta.2014.11.061

29. Astratine, L.; Magner, E.; Cassidy, J.; Betts, A. Electrochim. Acta, 2014, 115, 440. http://dx.doi.org/10.1016/j.electacta.2013.10.198

30. Algi, M. P.; Öztaş, Z.; Tirkes, S.; Cihaner, A.; Algi, F. Org. Electron. 2013, 14, 1094. http://dx.doi.org/10.1016/j.orgel.2013.01.036

31. Cao, Y.; Tao, Y. J.; Cheng, H. F.; Zhang, Z. Y. J. Appl. Polym. Sci. 2013, 129, 3764. http://dx.doi.org/10.1002/app.38778

32. Almeida, A. K. A.; Dias, J. M. M.; Silva, A. J. C.; Santos, D. P.; Navarro, M.; Tonholo, J.; Goulart, M. O. F.; Ribeiro, A. S. Electrochim. Acta, 2014, 122, 50.

http://dx.doi.org/10.1016/j.electacta.2013.10.008

33. Lichtman, J. W; Conchello, J-A. Nat. Meth. 2005, 2, 910.

http://dx.doi.org/10.1038/nmeth817 
34. Łapkowski, M.; Golba, S.; Żak, J.; Stolarczyk, A.; Sołoducho, J.; Doskocz, J.; Sulkowski, W.; Bartoszek, M. Polimery 2009, 54, 255.

35. Świst, A.; Cabaj, J.; Sołoducho, J.; Data, P.; Łapkowski, M. Synth. Met. 2013, 180, 1. http://dx.doi.org/10.1016/j.synthmet.2013.07.020

36. Sakong, C.; Kim, Y. D.; Choi, J.-H.; Yoon, C.; Kim, J. P. Dyes Pigments 2011, 88, 166. http://dx.doi.org/10.1016/i.dyepig.2010.06.003

37. Bahr, N.; Tierney, E.; Reymond, J.-L. Tetrahedron Lett. 1997, 38, 1489. http://dx.doi.org/10.1016/S0040-4039(97)00137-8

38. Garcia-Moreda, F. J.; Arregui, F. J.; Achaerandio, M.; Matias, J. R. Sensors Actuators B 2006, 118, 425. http://dx.doi.org/10.1016/j.snb.2006.04.079

39. Deiters, E.; Gumy, F.; Bunzli, J.-C. G. Eur. J. Inorg. Chem. 2010, 18, 2723. http://dx.doi.org/10.1002/ejic.200901148

40. Hsu, S. F.; Lee, C.-C.; Hu, A. T.; Chen, C. H. Curr. App. Phys. 2004, 4, 663. http://dx.doi.org/10.1016/j.cap.2003.11.067

41. Li, L.; Shi, Y.; Pan, L.; Shi, Y.; Yu, G. J. Mater. Chem. B, 2015, 3, 2920. http://dx.doi.org/10.1039/C5TB00090D

42. Jędrychowska, A.; Cabaj, J.; Świst, A.; Sołoducho, J. J. Electroanal. Chem. 2014, 720-721, 64. http://dx.doi.org/10.1016/j.jelechem.2014.03.017

43. Jędrychowska, A.; Malecha, K.; Cabaj, J.; Sołoducho, J. Electrochim. Acta 2015, 165, 372. http://dx.doi.org/10.1016/j.electacta.2015.03.044

\section{Autours' Biographies}

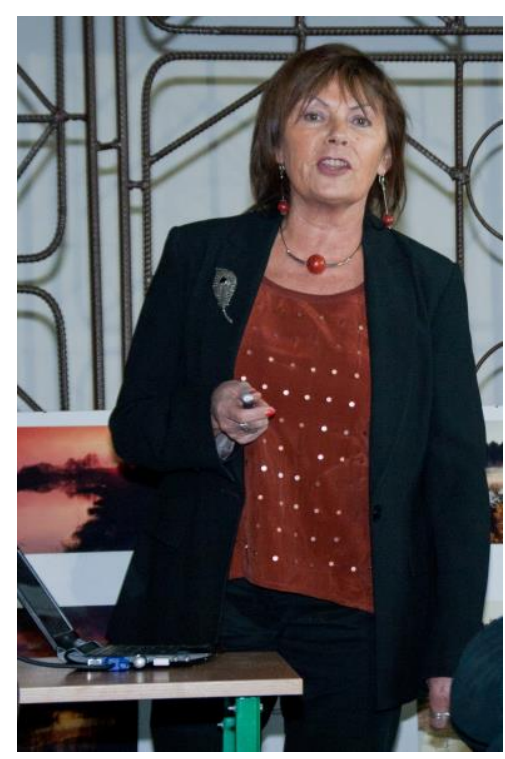

Professor Jadwiga Soloducho is an organic chemist; her interests are concerned with the synthesis and physicochemical properties of macromolecular heterocyclic structures. During 2002-2005 she was Head of the Institute of Organic Chemistry, Biochemistry and Biotechnology. During 2008-2012 she was vice-Dean of the Faculty of Chemistry of Wroclaw University of Technology, and from October 2012 to September 2015, Head of Department of Medicinal Chemistry and Microbiology of Wroclaw University of Technology. 
In recent years, Professor Sołoducho's researches have dealt with competitive materials for electronic and optoelectronic technologies. Her research work involves the synthesis of new organic monomers based on ethylenedioxythiophene, thiophene, thiazole, furan, thianthrene, xanthene, phenothiazine, phenoxazine, and tetraphenylsilane. In here field of interests, is also adequate correlations between electric intensity and toxic gases concentration. She also has interests in research directed into the properties of protein hybrid layers used as biosensors.

Professor J. Soloducho has been several times a recipient of awards by the Rectors of Wroclaw University of Technology (in example Docendo Discimus-2012, and gold award of Wrocław University of Technology-2013), and by Polish Science and Education Ministry (Maria Curie Sklodowska Award - the Brown medal, 2011). Since 1997 she has been also a co-organizer of the Lower Silesia Science Festival. She is an author of more than one hundred (120) original publications, eleven book chapters in international publishing houses, 63 patents and 21 patent declarations.

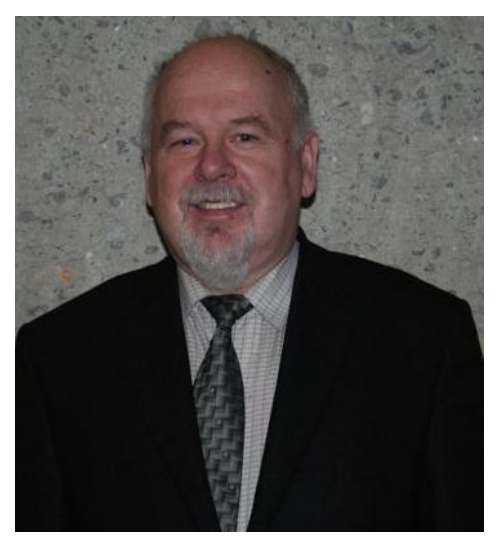

The Director of Department of Physical Chemistry and Technology of Polymers, Prof. Mieczyslaw Lapkowski has research interests and expertise which cover the following many areas: synthesis of electronic conducting polymers, the physicochemical characterization of polymers, oligomers and composite materials, synthesis and characterization of new organic materials for optoelectronics and photovoltaics. He gained important expertise in the field of conducting polymers by working in various research laboratories around the world, and particularly with the Nobel Prize winner in this field A. Heeger at the Uniax company. He is author or coauthor of 223 scientific publications, 4 books and 12 patents. He manages 12 projects funded by the Ministry of Science and Education in Poland and 2 funded by the National Science Foundation. For excellence in scientific research he was awarded the Cross of Merit, 1995, the Award of the Polish Chemical Society, 1991, the Scientific Award of the Minister of Science and Higher Education in 1983, and in 1991. 


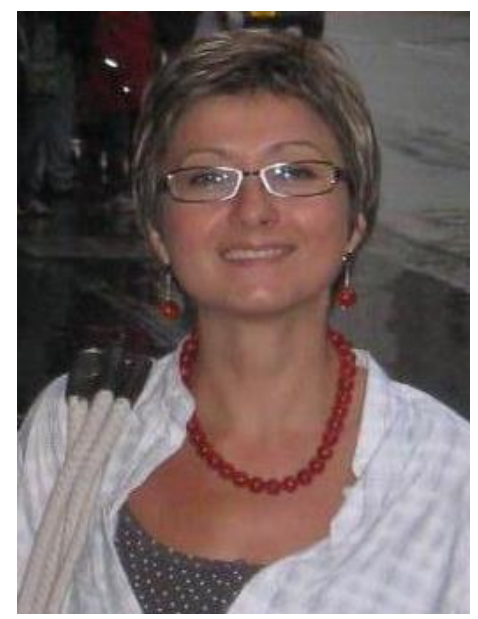

Joanna Cabaj, PhD, D. Sc. received her PhD in organic chemistry in Wroclaw University of Science and Technology, Poland, in 2005. After habilitation (2012, biotechnology) she worked as an assistant professor at the Faculty of Chemistry in Wroclaw University of Science and Technology. Her research interests include developing of novel semiconducting materials for molecular electronics and sensoric devices. After PhD, her main area of research has been connected with electroconducting properties of well-ordered thin LangmuirBlodgett and Langmuir-Schaefer films built of symmetric heterocyclic amphiphiles for construction of simple gas sensors. One of the most important research interests of Joanna Cabaj also include fabrication of small molecular biosensors (electrochemical, optical) based on enzymes immobilized in thin ordered layers obtained from synthesized macro-heterocyclic compounds. She has been co-author of 56 publications, 8 book chapters (international publishing houses) as well as 28 patents and several patent declarations. She was awarded the Rector of Wroclaw University of Science and Technology award for patent works in 2006 and 2007 and, as well, she was granted the young scientist award. Since $2010 \mathrm{~J}$. Cabaj is a Departmental Coordinator to Students Trainings according to the Erasmus + program.

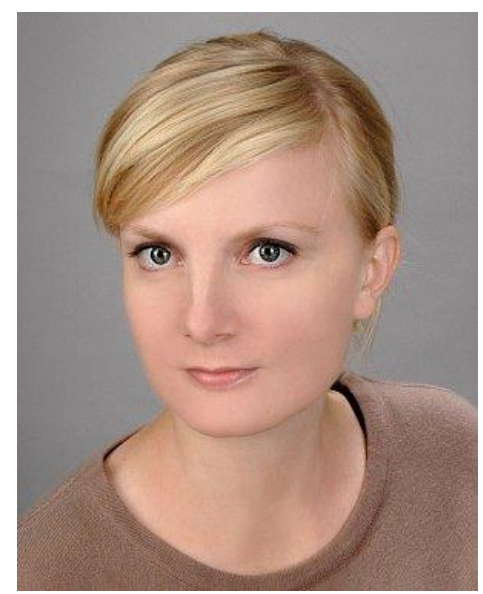

Dorota Zając is a PhD student at Wrocław University of Science and Technology. Her research interests include the chemistry of heterocyclic compounds, mainly the design and synthesis of heterocyclic systems with semiconductor properties which additionally may be used in potential applications in medical diagnostics and optoelectronic devices. She has been involved in a project aimed at the investigation and synthesis of tetraphenylsilane, dithienosilole and anthracene derivatives with conductive properties, which show donor acceptor or donor- $\pi$-spacer-acceptor motifs. Dorota Zając is co-author of 9 publications as well as 3 patents 
and 6 patent declarations. Furthermore, she is the recipient of a scholarship for the best doctoral students of Wrocław University of Science and Technology (years 2012-2014 and 2015-2016). 